\title{
Van Wyk Grumbach Syndrome
}

\author{
Maira Riaz, Mohsina Noor Ibrahim, Taj Muhammad Laghari, Misbah Iqbal Hanif and Jamal Raza \\ Department of Paediatrics, National Institute of Child Health, Karachi, Pakistan
}

\begin{abstract}
Van Wyk Grumbach syndrome is well known for protracted hypothyroidism, characterised by multicystic ovaries (normal size ovaries contain many follicles of various sizes), isosexual precocious puberty and delayed skeletal growth. A series of ten children with Van Wyk Grumbach syndrome is been presented with their clinical features, biochemical and radiological profile and management. Patients showed a noteworthy improvement upon thyroxine therapy. It is vital to keep this entity in consideration and; hence, should investigate for thyroid status during the evaluation of ovarian cysts. Thyroxin replacement after establishing the diagnosis early can prevent the patient from going through extensive workup and surgeries.
\end{abstract}

Key Words: Hypothyrodism, Multicystic ovaries, Isosexual precocious puberty.

How to cite this article: Riaz M, Ibrahim MN, Laghari TM, Hanif MI, Raza J. Van Wyk Grumbach Syndrome. J Coll Physicians Surg Pak 2020; 30(12):1332-1334.

\section{INTRODUCTION}

Van Wyk Grumbach syndrome (VWGS) is described as a relatively rare manifestation of prolonged untreated hypothyroidism. ${ }^{1}$ In female patients, VWGS is characterised by isosexual precocious puberty in the form of vaginal bleeding, breast enlargement or galactorhea, ovarian mass or cysts and lack of pubic or axillary hairs (incomplete adrenarche), ${ }^{2}$ while it presents with testicular enlargement and minimal penile enlargement in male patients. ${ }^{3}$ Other classical characteristic features include delayed bone age and short stature. However, noticeable improvements have been observed with thyroid hormone treatment in terms of precocity as well as ovarian cysts, which VWG labelled as an integral part of this disorder. ${ }^{4}$

A series of ten cases of children with VWGS is described in this article, who were timely diagnosed and cured at endocrine OPD of a tertiary care hospital.

\section{METHODOLOGY}

After approval from the IERB of the suspected cases of hypothyroidism were critically analysed by two of the authors who are pediatric endocrinologist. All the patients with precocious puberty were enrolled in the study during November 2017 and March 2020, though who were confirmed with VWGS are only being presented in the case series.

Correspondence to: Dr. Misbah Iqbal Hanif, Department of Paediatrics, National Institute of Child Health, Karachi, Pakistan

E-mail: misbahhanif88@outlook.com

Received: August 06, 2020; Revised: October 15, 2020;

Accepted: November 02, 2020

DOI: https://doi.org/10.29271/jcpsp.2020.12.1332
Diagnostic confirmation was done on the basis of their clinical examination, karyotyping and hormonal work up (Serum TSH, T4, FSH and LH) and systemic evaluation including (abdomen, pelvis, cardiac and eye examination). All the data of medical importance along with their demography was recorded. X-rays and MRI were analysed by a radiologist for the prospected abnormalities and therapeutic responses. Ethical permission was taken from the institutional ethical review board to collect the medical information from the patients diagnosed with VWGS. Each child was thoroughly informed about the study, and written informed consent wastaken.

\section{RESULTS}

A total of 10 patients, aged between 6-18 years, all had 46 XX karyotype with confirmed diagnosis of VWGS were recruited in this case series. The major complaints were short stature which was $<3^{\text {rd }}$ percentile, irregular vaginal bleeding, abdominal pain, anemia and in one patient prematurethelarche. Physical examination showed six patients had signs of precocious puberty (pervaginum bleeding and breast enlargement) and incomplete adrenarche (scanty pubic hairs) in two children. All children had delayed bone age on radiographs. Two girls approached the clinic for the complaint of abdominal pain and distension followed by vomiting and difficulty in breathing. There was history of headache in three girls but no visual field defects found in any.

A case of retinitis pigmentosa was also identified with non-reactive pupils. One patient with antithyroid peroxidase antibody positive incidentally showed ejection systolic murmur, confirmed to be Tetralogy of Fallout's on echocardiogram. On ultrasound (U/S) thyroid gland was not visualised in all girls except one, who showed small inhomogeneous thyroid gland. Upon U/S abdomen and MRI, five girls showed enlarged bulky uterus with thickened endometrial cystic lesion. Almost all girls had multiple cystic ovaries, which regressed after thyroxin replacement in 3 to 6 months duration. 
Table I: Biochemical profile of all the children.

\begin{tabular}{|c|c|c|c|c|c|c|c|c|}
\hline No. & $\begin{array}{c}\text { TSH } \\
\text { Level IU/mI }\end{array}$ & $\begin{array}{c}\text { FT4 } \\
\mathrm{ng} / \mathrm{dl}\end{array}$ & $\begin{array}{c}\text { Prolactin } \\
\mathrm{ng} / \mathrm{ml}\end{array}$ & Ani TPo & Anti thyroglobulin & LH & FSH & Estradiol \\
\hline & $0.1-5.7 \mathrm{IU} / \mathrm{ml}$ & $0.8-1.9$ & $3-20$ & $\mathrm{IU} / \mathrm{ml}$ & IU/ml & $<0.1 \mathrm{mlU} / \mathrm{ml}$ & $<0.2 \mathrm{mlU} / \mathrm{ml}$ & $6-27 \mathrm{pg} / \mathrm{ml}$ \\
\hline 1 & 9.31 & 1.68 & 65.9 & 11.9 & $<20$ & & & 30 \\
\hline 2 & 8 & 2.51 & 10.0 & 35.9 & $<20$ & & & 18 \\
\hline 3 & 50 & 0.27 & 12.0 & 6.9 & $<20$ & 0.315 & 0.975 & 17 \\
\hline 4 & 20 & $<0.30$ & 45.40 & & & 0.40 & 3.61 & 364 \\
\hline 5 & $>100$ & 0.73 & 199 & & & 0.1 & 4.9 & 23 \\
\hline 6 & $>50$ & 0.09 & 70.5 & & & $<0.1$ & 10.03 & 70.2 \\
\hline 7 & $>150$ & 0.38 & 23.0 & & & 0.81 & 5.2 & 10 \\
\hline 8 & 30 & 0.56 & 24 & & & 0.78 & 13.2 & 42 \\
\hline 9 & $>50$ & 0.87 & 11 & & & & & \\
\hline 10 & $>50$ & 0.32 & 8.3 & & & & & \\
\hline
\end{tabular}

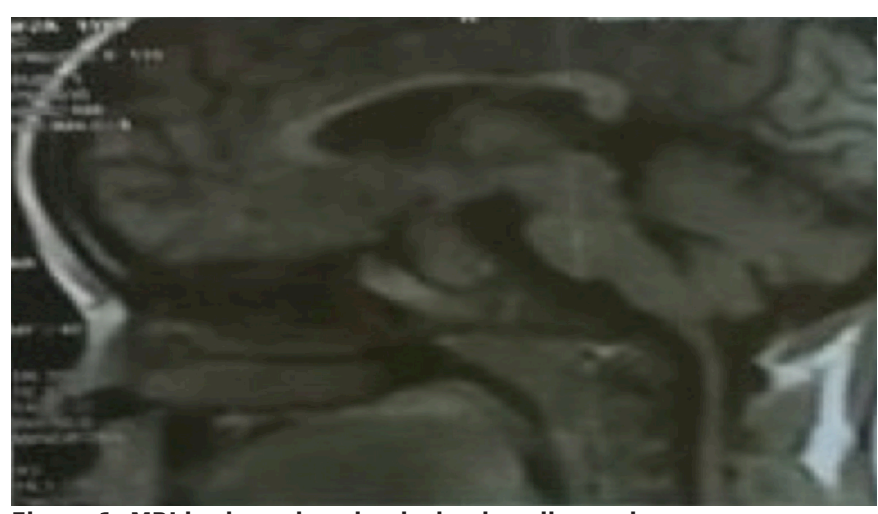

Figure 1: MRI brain; enhancing lesion in sellar region.

Histopathology of the abdominal mass inseparable from the left ovary showed germ cell tumor in one girl who was of 19 years chronologically with severe short stature and bone age of only 8 years. She also had multiple fairly defined hyperechoic areas in right lobe of the liver confirmed through CT scan which gradually was reduced upon treatment. Both CA 125 and AFP were declined to normal and adnexal mass size reduced completely along with liver lesions after thyroxine replacement. Another patient had left salpingo oophorectomy on laparotomy secondary to acute abdomen. MRI of the children presented with pituitary enlargement in twothirds of the total cases (Figure 1). All patients proved promising improvement with regression of their ovarian cyst/mass size, and pituitary gland enhancement with increase in their linear growth. Biochemical profile of all the children is mentioned in Table I.

\section{DISCUSSION}

All cases recorded in this series were girls $(46, \mathrm{XX}$ on karyotyping) but it has been reported in boys as well. ${ }^{3,5}$ In many case studies, this syndrome found to be associated with ovarian mass or multicystic ovaries as in our case series, ${ }^{2,6-8}$ that may be due to myxedematous infiltration of the ovaries. To the authors' knowledge, Kumar et al. reported the only case series of VWGS without ovarian cysts on imaging. ${ }^{9}$

TSH levels were consistently elevated in all of these patients, which acts directly on FSH receptors causing precocity in them as postulated in many other studies. ${ }^{2,5}$ One of these cases and few other cases in past reported a raised CA 125 level. ${ }^{8,10}$ Another one showed raised AFP level and had oophorectomy like several others reported in literature. ${ }^{4,8}$ On biopsy of the specimen, it was found to be cystic and not neoplastic.

Seven out of ten patients in this series showed pituitary gland enlargement or enhanced sellar region suggesting pituitary hyperplasia like other reviews available, ${ }^{4,5}$ Previous reports notified autoimmune thyroid disease to be the major cause of hypothyroidism in VWGS but there are some case reports where the syndrome is secondary to unrecognised congenital hypothyroidism, like most of these cases. ${ }^{4,7}$

Half of these patients were found to be anemic, which could be secondary to their vaginal bleeding from precocious puberty, or directly due to their hypothyroid state. This is also similar to Baranowski et al. and Hunold et al. case reports. ${ }^{7,10}$ Although VWGS has been reported with Down syndrome many times in literature., ${ }^{4,6}$ but there was no case report with retinitis pigmentosa and Tetralogy of Fallot with VWGS as in this case series. Finally, the delayed bone age is categorically associated with untreated long standing hypothyroidism. ${ }^{3-5,7}$ Precocious puberty secondary to causes other than VWGS mostly present with bone age advanced.

\section{CONCLUSION}

Conservative treatment remains the first-line approach to massive ovarian cysts caused by hypothyroidism. Tumor markers, ovarian cysts and isosexual precocious puberty can all reverse to normal with proper medical management. So precocious girls with ovarian cysts should be evaluated for VWGS before sending them for extensive investigations and surgical misadventures.

\section{ETHICAL APPROVAL:}

This study was conducted after the approval of Institutional Ethical Review Committee. 


\section{PATIENTS' CONSENTS:}

Patients were thoroughly informed prior to the study and consents were also obtained.

\section{CONFLICT OF INTEREST:}

There was no conflict of interest among authors.

\section{AUTHORS' CONTRIBUTION:}

MR: Study design, conceptualisation, data collection and interpretation, manuscript, writing.

MNI: Data, interpretation and concentration.

TL: Data interpretation, manuscript editing.

MIH: Data collection, manuscript writing.

JR: Final approval of the version to be published.

\section{REFERENCES}

1. Reddy P, Tiwari K, Kulkarni A, Parikh K, Khubchandani R. Van Wyk Grumbach syndrome: A rare consequence of hypothyroidism. Indian J Pediatr 2018; 85(11):1028-30. doi: 10.1007/s12098-018-2704-2.

2. Rastogi A, Bhadada SK, Bhansali A. An unusual presentation of a usual disorder: Van Wyk-Grumbach syndrome. Indian J Endocrinol Metab 2011; 15(Suppl2): S141. doi: 10.4103/2230-8210.83356.

3. Omran A, Peng J, Shrestha B, Ashhab MU, Yin F. Male child with Van Wyk-Grumbach's syndrome and other complications of long-standing primary hypothyroidism: A case report. Case Rep Pediatr 2012; 2012. doi: 10.1155/ 2012/352751.
4. Ayub SS, Ruzic A, Taylor JA. Ovarian cysts, vaginal bleeding and hypothyroidism in a 4-year-old female with down syndrome: A case of Van Wyk-Grumbach syndrome. J Pediatric Surg Case Reports 2017; 25:5-9. doi.org/10/ 1016/j.epsc.2017.07.007.

5. Zhang S, Yang J, Zheng R, Jiang L, Wei Y, Liu G. VanWyk-Grumbach syndrome in a male pediatric patient: A rare case report and literature review. Exp Ther Med 2017; 13(3):1151-4. doi.org/10.3892/etm.2017.4086.

6. Lim HH, Kil HR, Kim JY. Unusual presentations of a girl with Down syndrome: Van Wyk-Grumbach syndrome. J Pediatr Endocrinol Metab 2012; 25(11-12):1209-12. doi: 10.1515/ jpem-2012-0195.

7. Baranowski E, Högler W. An unusual presentation of acquired hypothyroidism: The Van Wyk-Grumbach syndrome. EurJ Endocrinol 2012; 166(3):537. doi: 10.1530/ EJE-11-0494.

8. Durbin KL, Diaz-Montes T, Loveless MB. Van Wyk and Grumbach syndrome: An unusual case and review of the literature. J Pediatric Adolescent Gynecol 2011; 24(4): e93-6. doi: 10.1016/j.jpag.2010.08.003.

9. Kumar KH, Muthukrishnan J, Sinha R, Modi KD. Two cases describing the effects of hypothyroidism on puberty and growth. Int J Gynaecol Obstetrics 2008; 103(2):183. doi: 10.1016/j.ijgo.2008.05.018.

10. Hunold A, Alzen G, Wudy SA, Bluetters-Sawatzki R, Landmann E, Reiter A, Wagner HJ. Ovarian tumor in a 12-year old female with severe hypothyroidism: A case of Van Wyk and Grumbach syndrome. Pediatric Blood Cancer 2009; 52(5):677-9. doi: 10.1002/pbc.21920. 